Research Article

\title{
Simultaneous Quantitative Determination of Polyphenolic Compounds in Blumea balsamifera (Ai-Na-Xiang, Sembung) by High-Performance Liquid Chromatography with Photodiode Array Detector
}

\author{
Daopeng Tan, ${ }^{1,2}$ Zhou Yang, ${ }^{3}$ Qianru Zhang, ${ }^{1}$ Hua Ling, ${ }^{4}$ Yimei Du, ${ }^{1}$ Yanliu Lu, ${ }^{3}$ \\ Tianpei Xie, ${ }^{3}$ Xumei Zhou, ${ }^{1}$ Lin Qin $\mathbb{D}^{1},{ }^{1}$ and Yuqi He $\mathbb{D}^{1}$ \\ ${ }^{1}$ Key Laboratory of Basic Pharmacalogy of Ministry of Education and Joint International Research Laboratory of \\ Ethnomedicine of Ministry of Education, School of Pharmacy, Zunyi Medical University, Guizhou 563009, China \\ ${ }^{2}$ State Key Laboratory of Functions and Applications of Medicinal Plants, Guizhou Medical University, Guiyang 550014, China \\ ${ }^{3}$ Shanghai Nature-Standard Technical Service Co., Ltd., Shanghai 201203, China \\ ${ }^{4}$ School of Pharmacy, Georgia Campus-Philadelphia College of Osteopathic Medicine, 625 Old Peachtree Rd NW, Suwanee, \\ GA 30024, USA
}

Correspondence should be addressed to Lin Qin; qinlin1115@163.com and Yuqi He; HyqJeff@foxmail.com

Received 23 September 2019; Revised 4 December 2019; Accepted 10 January 2020; Published 18 March 2020

Academic Editor: Kevin Honeychurch

Copyright (c) 2020 Daopeng Tan et al. This is an open access article distributed under the Creative Commons Attribution License, which permits unrestricted use, distribution, and reproduction in any medium, provided the original work is properly cited.

\begin{abstract}
A high-performance liquid chromatography method was developed for simultaneous quantification of 18 polyphenolic compounds from the leaves of Blumea balsamifera, including 17 flavonoids and 1 phenylethanone. The B. balsamifera extraction was separated by a Kromasil $\mathrm{C}_{18}$ column $(250 \times 4.6 \mathrm{~mm}, 5 \mu \mathrm{m})$ with a binary gradient mobile phase consisting of acetonitrile and $0.2 \%$ aqueous acetic acid. A photodiode array detector (PDA) was used to record the signals of investigated constituents. The linearity, sensitivity, stability, precision, and accuracy of the established assay methods were assessed to meet the requirements of quantitative determination. Samples extracted by reflux in $25 \mathrm{~mL}$ of $80 \%$ methanol for 30 minutes were selected for the extraction method. The 18 compounds were accurately identified by comparing with the reference compounds. The purity of each peak was confirmed by the base peak in the mass spectrum. The contents of 18 compounds in Blumea samples from four different regions were successfully determined. The results also showed that 3,3',5,7-tetrahydroxy-4'-methoxyflavanone was the most abundant constituent, which could be used as a potential chemical marker for quality control of B. balsamifera and Chinese patent medications containing $B$. balsamifera herb.
\end{abstract}

\section{Introduction}

Blumea balsamifera (Compositae) is a medicinal plant widely growing in China and Southeast Asian countries such as Malaysia, Philippines, Vietnam, and Thailand. In China, it is called as Ai-Na-Xiang, whereas in Philippines it is called Sembung. B. balsamifera showed lots of biological effects on stomach, respiratory system [1], nervous system [2], and also showed sudorific [3], antifungal [4], anticancer $[5,6]$, and antiobesity [4] effects.
Leaves of B. balsamifera are sometimes used as tea and cigarettes. It contains abundant flavonoids [7-12] that are a ubiquitous group of polyphenolic substances. Similar to the whole plant of $B$. balsamifera, flavonoids from leaves of $B$. balsamifera also showed broad pharmacological activities such as radical scavenging [10, 13], anticancer [14, 15], plasmin-inhibition [16], liver-protection [17] and xanthine oxidase inhibitory effects [12].

Quality control is crucial to guarantee the safety and efficacy of the utilization of herbal medicines. Unlike the 


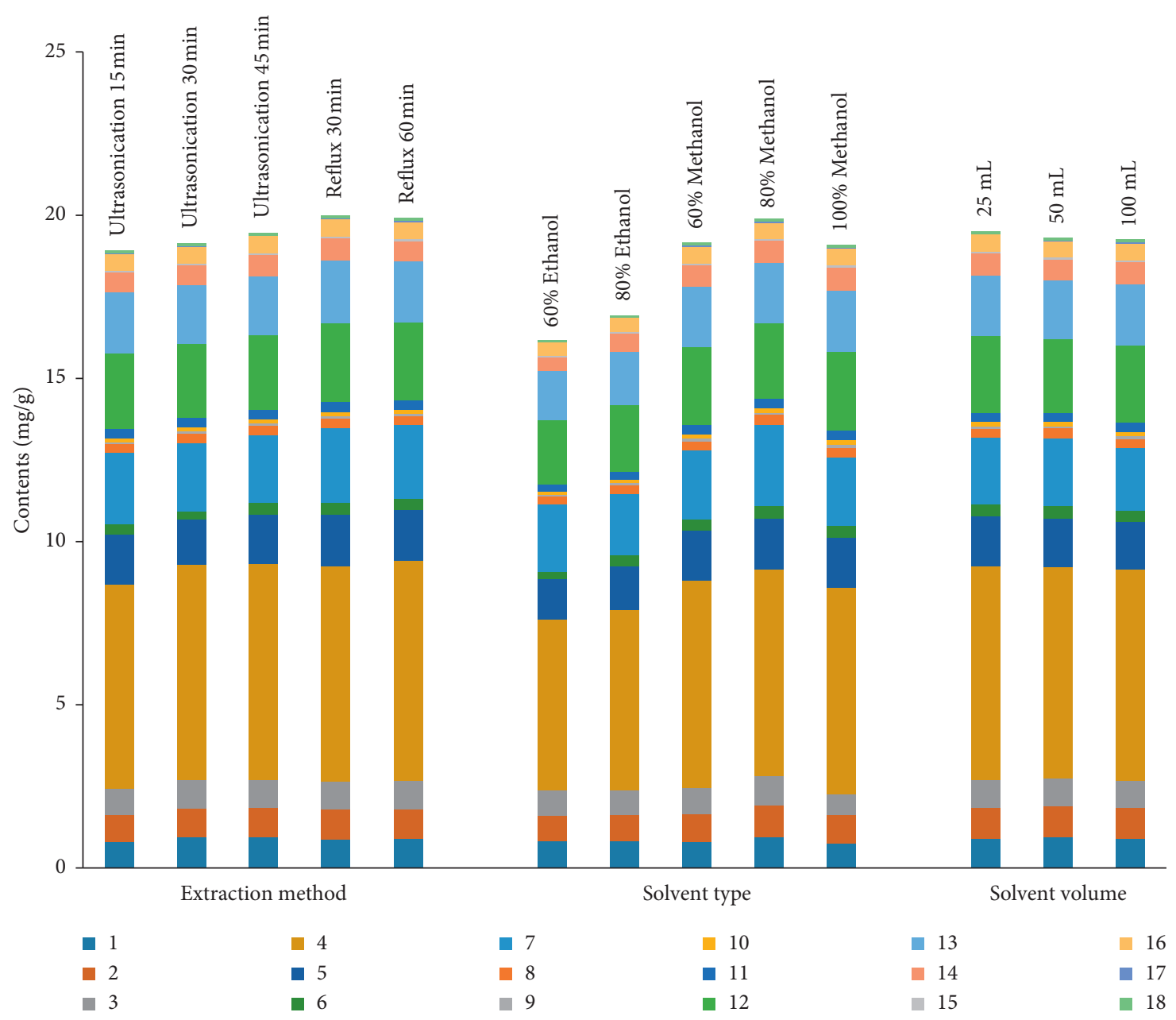

Figure 1: Effects of the extraction method, solvent type, and solvent volume on the extraction efficiency of 18 constituents in the leaves of $B$. balsamifera (1, Rutin; 2, Hyperoside; 3, Isoquercitrin; 4, 3,3',5,7-Tetrahydroxy-4' -methoxyflavanone; 5, 3',5,5',7-Tetrahydroxyflavanone; 6, Quercetin; 7, 3,3', $4^{\prime}, 5$-Tetrahydroxy-7-methoxyflavanone; 8, Chrysosplenol C; 9, Diosmetin; 10, Tamarixetin; 11, 3,5,7-Trihydroxy-3', $4^{\prime}$ dimethoxyflavone; 12, 3,3', 5 -Trihydroxy-4',7-dimethoxyflavanone; 13, Blumeatin; 14, Rhamnetin; 15, 3', $4^{\prime}, 5$-Trihydroxy-3,7-dimethoxyflavone; 16, Xanthoxylin; 17, Ombuin; 18, 3,5-Dihydroxy-3', $4^{\prime}, 7$-trimethoxyflavone). When one parameter was determined, the others were set at the default value.

synthetic drugs, the effectiveness of herbal medicines may be attributed to the overall effect of several components rather than a single component. Moreover, the synergistic effect between components is also related to herb efficacy. Thus, the quality evaluation of herbal medicine is very difficult and requires the information of bioactive components as much as possible. Several studies have reported the determination of constituents in B. balsamifera [18]. However, most of them have focused on only a few components. To the best of our knowledge, only one article showed a determination of 5 flavonoids in the leaves of B. balsamifera [19]; however, it requires a tedious sample preparation procedure.

High-performance liquid chromatography (HPLC) coupled with various detectors such as ultraviolet-visible (UV) detection [20], photodiode array (PDA) detection [21], and mass spectrometry (MS) [22] are accepted methods applied in herb quality control. Among them, HPLC coupled with PDA (HPLC-PDA) is the preferred method used in pharmaceutical industry because of its high efficiency and low cost.

In the present study, we developed a simple HPLC-PDA method to simultaneously determine 18 bioactive compounds in the leaves of B. balsamifera. The established method was simple, reliable, and high throughout and would be potentially used to control the quality of $B$. balsamifera precisely.

\section{Materials and Methods}

2.1. Materials and Chemicals. Four batches of the leaves of $B$. balsamifera were collected from Guizhou, Guangxi, Yunnan province of China. The sample materials were identified by Dr. Daopeng Tan as the leaves of B. balsamifera. 
<smiles>[R3]c1ccc(-c2oc3cc([R3])c([R])c(O)c3c(=O)c2[R])cc1[R9]</smiles>

$\begin{array}{cllcccc}\text { No. Name } & \mathrm{R}_{1} & \mathrm{R}_{2} & \mathrm{R}_{3} & \mathrm{R}_{4} & \mathrm{R}_{5} \\ 1 & \text { Rutin } & \text { ORutinose } & \mathrm{H} & \mathrm{OH} & \mathrm{OH} & \mathrm{OH} \\ 2 & \text { Hyperoside } & \text { OGal } & \mathrm{H} & \mathrm{OH} & \mathrm{OH} & \mathrm{OH} \\ 3 & \text { Isoquercitrin } & \mathrm{OGlc} & \mathrm{H} & \mathrm{OH} & \mathrm{OH} & \mathrm{OH} \\ 6 & \text { Quercetin } & \mathrm{OH} & \mathrm{H} & \mathrm{OH} & \mathrm{OH} & \mathrm{OH} \\ 8 & \text { Chrysosplenol C } & \mathrm{OCH}_{3} & \mathrm{OH} & \mathrm{OCH}_{3} & \mathrm{OH} & \mathrm{OCH}_{3} \\ 9 & \text { Diosmetin } & \mathrm{H} & \mathrm{H} & \mathrm{OH} & \mathrm{OCH}_{3} & \mathrm{OH} \\ 10 & \text { Tamarixetin } & \mathrm{OH} & \mathrm{H} & \mathrm{OH} & \mathrm{OCH}_{3} & \mathrm{OH} \\ 11 & \text { 3,5,7-Trihydroxy-3',4'-dimethoxyflavone } & \mathrm{OH} & \mathrm{H} & \mathrm{OH}^{-} & \mathrm{OCH}_{3} & \mathrm{OCH} \\ 14 & \text { Rhamnetin } & \mathrm{OH} & \mathrm{H} & \mathrm{OCH}_{3} & \mathrm{OH} & \mathrm{OH} \\ 15 & \text { 3',4',5-Trihydroxy-3,7-dimethoxyflavone } & \mathrm{OCH} & \mathrm{H} & \mathrm{OCH}_{3} & \mathrm{OH} & \mathrm{OH} \\ 17 & \text { Ombuin } & \mathrm{OH} & \mathrm{H} & \mathrm{OCH}_{3} & \mathrm{OCH}_{3} & \mathrm{OH} \\ 18 & \text { 3,5-Dihydroxy-3',4',7-trimethoxyflavone } & \mathrm{OH} & \mathrm{H} & \mathrm{OCH}_{3} & \mathrm{OCH}_{3} & \mathrm{OCH}\end{array}$<smiles>[R]c1cc(O)c2c(c1)OC(c1cc([13CH3])c([R3])c(O)c1)C([R3])C2=O</smiles>

FigURE 2: The structures of 18 reference standards isolated from the leaves of B. balsamifera.

A total of 18 reference compounds including 17 flavonoids and 1 phenylethanone (Figure 1) were isolated previously from the leaves of $B$. balsamifera in our laboratory and elucidated by NMR and MS $[23,24]$. The purities of these reference standards were higher than $98.0 \%$ checked by the HPLC method.
HPLC grade acetonitrile (Merck, Germany) was used as the mobile phase. All other reagents were at least analytical grade (Jinhuada Chemical Factory, Guangzhou, China). Water was purified using a Milli-Q water purification system (Millipore, USA). 


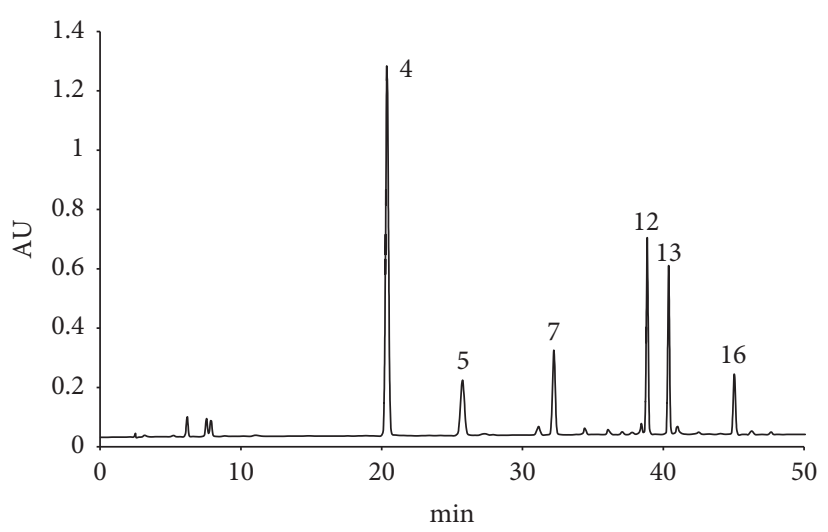

(a)

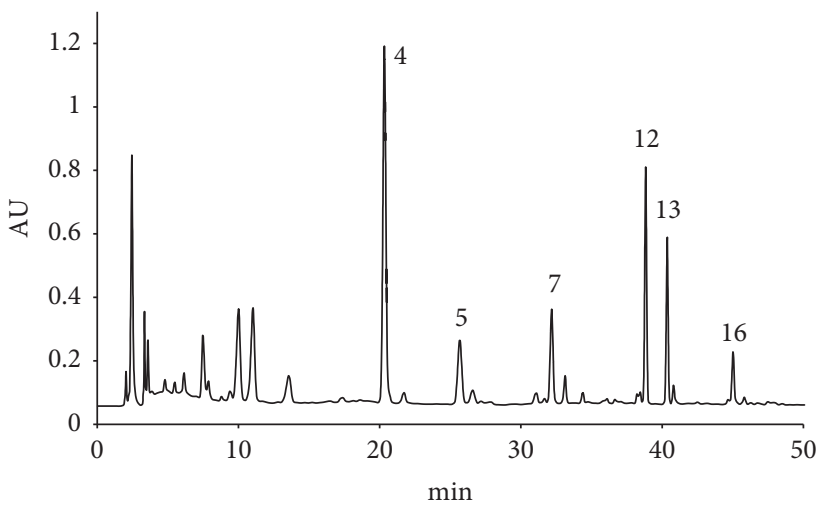

(c)

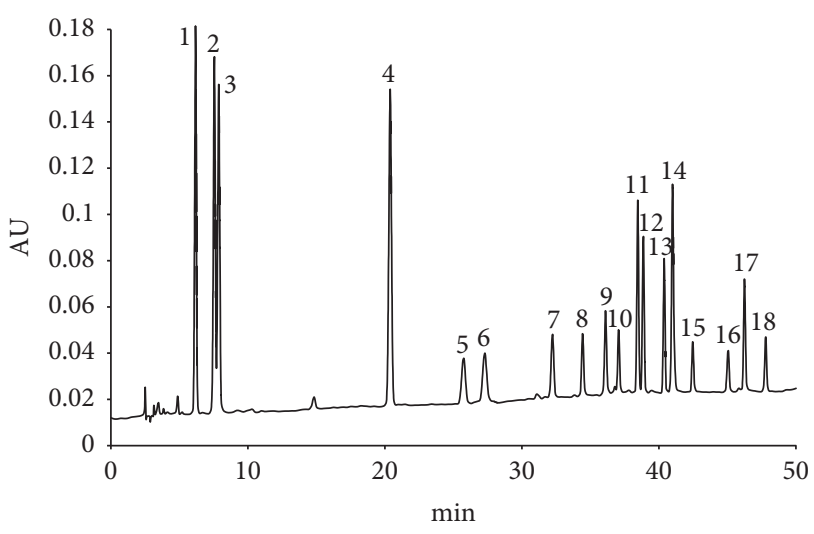

(b)

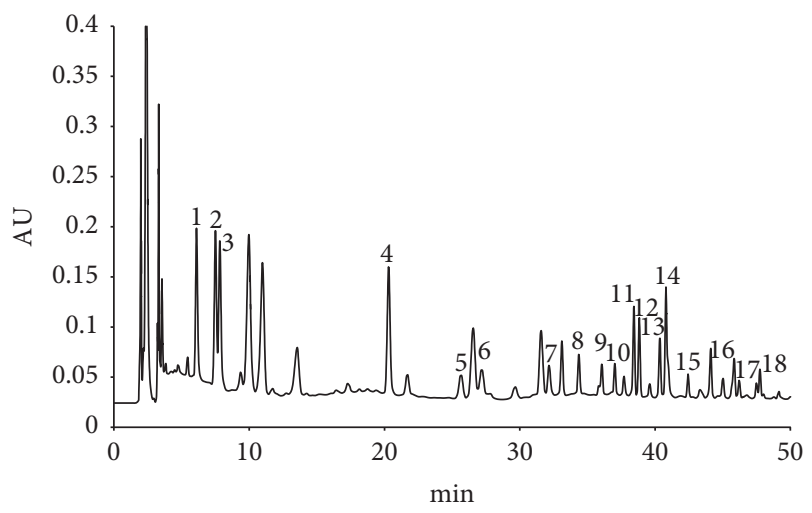

(d)

Figure 3: HPLC chromatographs. ((a) Reference standards at $289 \mathrm{~nm}$; (b) reference standards at $254 \mathrm{~nm}$; (c) the sample of batch no. GZ20151001 at $289 \mathrm{~nm}$; (d) the sample of batch no. GZ20151001 at $254 \mathrm{~nm}$; 1, Rutin; 2, Hyperoside; 3, Isoquercitrin; 4, 3,3',5,7-Tetrahydroxy-4'-methoxyflavanone; 5, 3',5,5',7-Tetrahydroxyflavanone; 6, Quercetin; 7, 3,3', $4^{\prime}, 5$-Tetrahydroxy-7-methoxyflavanone; 8, Chrysosplenol C; 9, Diosmetin; 10, Tamarixetin; 11, 3,5,7-Trihydroxy-3' ${ }^{\prime} 4^{\prime}$-dimethoxyflavone; 12, 3,3',5-Trihydroxy-4 $4^{\prime}, 7$-dimethoxyflavanone; 13, Blumeatin; 14, Rhamnetin; 15, 3', $4^{\prime}, 5$-Trihydroxy-3,7-dimethoxyflavone; 16, Xanthoxylin; 17, Ombuin; 18, 3,5-Dihydroxy$3^{\prime}, 4^{\prime}, 7$-trimethoxyflavone).

2.2. Sample Preparation. The ground dried leaves of $B$. balsamifera were dried and pulverized into a homogeneous powder mixture (60 meshes). The powder $(0.6 \mathrm{~g})$ was extracted by reflux in $80 \%$ methanol $(25 \mathrm{~mL})$ for $30 \mathrm{~min}$. The extracted sample solution was filtered with a $0.45 \mu \mathrm{m}$ membrane prior to the HPLC analysis.

The reference standards were accurately weighed and dissolved in methanol to prepare mixed standard stock solution. Consisted of each reference compounds 1-18 in the mixed standard stock solution were $233.2 \mu \mathrm{g} / \mathrm{mL}$, $211.1 \mu \mathrm{g} / \mathrm{mL}, \quad 195.3 \mu \mathrm{g} / \mathrm{mL}, \quad 1669.0 \mu \mathrm{g} / \mathrm{mL}, \quad 330.5 \mu \mathrm{g} / \mathrm{mL}$, $57.3 \mu \mathrm{g} / \mathrm{mL}, 443.5 \mu \mathrm{g} / \mathrm{mL}, 51.6 \mu \mathrm{g} / \mathrm{mL}, 25.8 \mu \mathrm{g} / \mathrm{mL}, 28.1 \mu \mathrm{g} /$ $\mathrm{mL}, \quad 68.3 \mu \mathrm{g} / \mathrm{mL}, \quad 534.2 \mu \mathrm{g} / \mathrm{mL}, 447.9 \mu \mathrm{g} / \mathrm{mL}, 125.5 \mu \mathrm{g} / \mathrm{mL}$, $15.7 \mu \mathrm{g} / \mathrm{mL}, 123.8 \mu \mathrm{g} / \mathrm{mL}, 16.9 \mu \mathrm{g} / \mathrm{mL}$, and $20.2 \mu \mathrm{g} / \mathrm{mL}$, respectively. The mixed standard stock solution was stored at $4^{\circ} \mathrm{C}$ without exposure of light for further analysis. Working standard solutions used to prepare calibration curves and check recovery were prepared by diluting the standard stock solution into serial concentrations with methanol. The standard solutions were filtered through a $0.45 \mu \mathrm{m}$ membrane prior to the HPLC analysis.
2.3. Chromatography Parameters. The HPLC system consists of a Waters 2995 controller and 2998 Photodiode Array detector. The separation was performed on an Elite Kromasil $\mathrm{C}_{18}$ column $(250 \mathrm{~mm} \times 4.6 \mathrm{~mm}, 5 \mu \mathrm{m})$. The flow rate was set at $1.0 \mathrm{~mL} / \mathrm{min}$, with the column temperature set at $25^{\circ} \mathrm{C}$, and detective wavelength was set at 254 and $289 \mathrm{~nm}$. The acetonitrile and water containing $0.2 \%$ acetic acid were employed as mobile phases $\mathrm{A}$ and $\mathrm{B}$, respectively. The binary gradient program was set as follows: $0-10 \mathrm{~min}, 80 \%$ of B; $10-15 \mathrm{~min}, 80$ to $75 \%$ of $\mathrm{B} ; 15-25 \mathrm{~min}, 75 \%$ of $\mathrm{B} ; 25-50 \mathrm{~min}, 75$ to $35 \%$ of $\mathrm{B}$; and equilibrated for $10 \mathrm{~min}$ before the next injection. The injection volume was $10 \mu \mathrm{L}$. Data were collected and visualized by Waters Empower Chemstation Software.

The chromatographic peak purity analysis was performed on an Agilent 1290 UPLC system coupled with a SCIEX Triple TOF 4600 mass spectrometer equipped with an ESI interface. The optimized MS conditions were as follows: TOF mass range between 50 and 1700, curtain gas $35 \mathrm{psig}$, ion spray voltage floating $-4500 / 5000 \mathrm{kV}$, and ion source temperature $500^{\circ} \mathrm{C}$. The collision energy was set at $10 \mathrm{~V}$ to obtain more fragment information. 

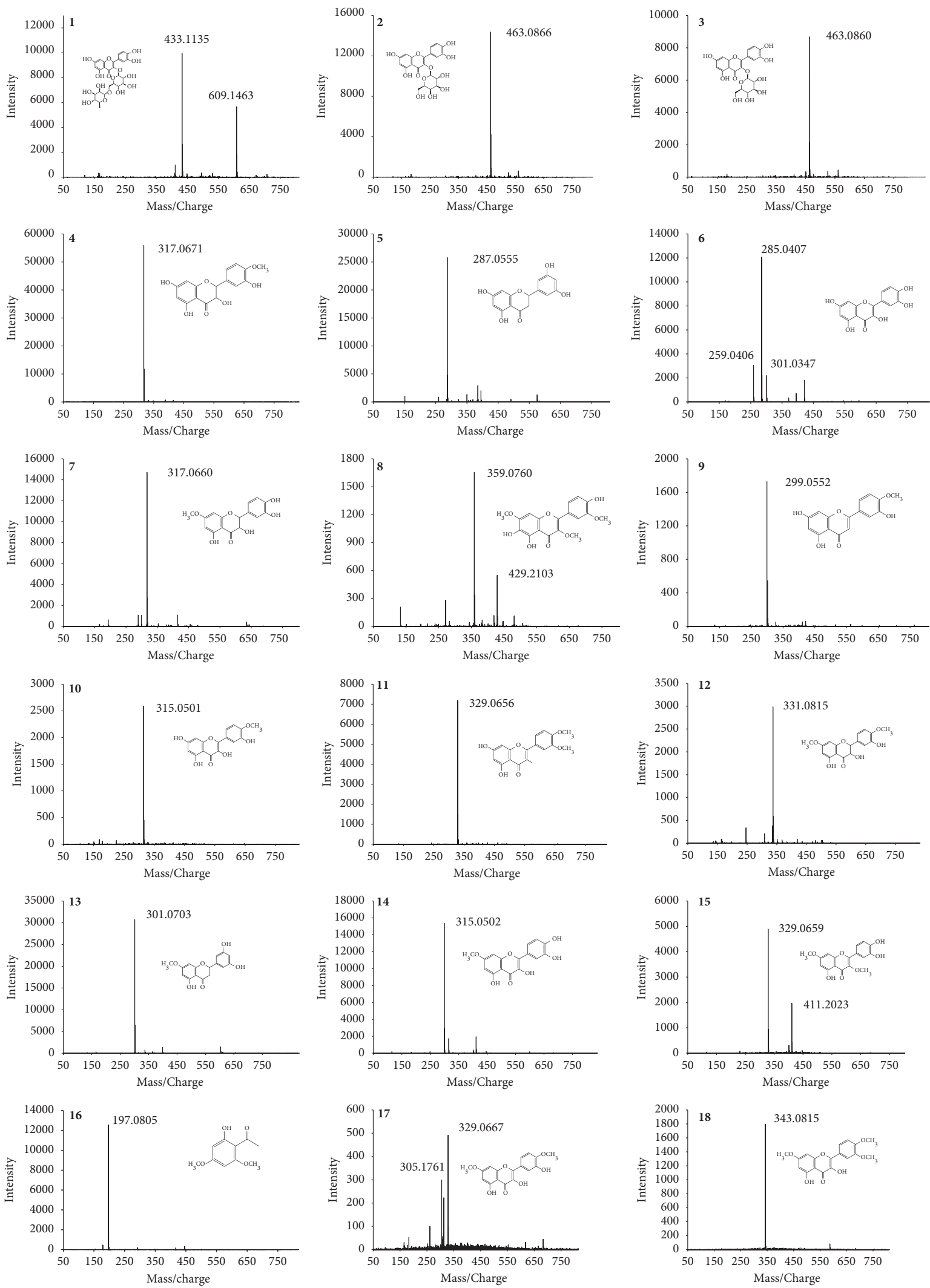

Figure 4: MS spectrum (ESI ${ }^{-}$for 1, Rutin; 2, Hyperoside; 3, Isoquercitrin; 4, 3,3',5,7-Tetrahydroxy-4'-methoxyflavanone; 5, 3' 3 $^{\prime}$, $5^{\prime}, 7$ Tetrahydroxyflavanone; 6, Quercetin; 7, 3,3' $4^{\prime}, 5$-Tetrahydroxy-7-methoxyflavanone; 8, Chrysosplenol C; 9, Diosmetin; 10, Tamarixetin; 11, 3,5,7-Trihydroxy-3', $4^{\prime}$-dimethoxyflavone; 12, 3,3',5-Trihydroxy-4',7-dimethoxyflavanone; 13, Blumeatin; 14, Rhamnetin; 15, 3', $4^{\prime}, 5$-Trihydroxy-3,7-dimethoxyflavone; 17, Ombuin; 18, 3,5-Dihydroxy-3' $4^{\prime}, 7$-trimethoxyflavone; ESI ${ }^{+}$for 16, Xanthoxylin). 
TABLE 1: Linearity and sensitivity of the HPLC analysis.

\begin{tabular}{|c|c|c|c|c|c|c|}
\hline No. & Compound name & Calibration curve $^{\mathrm{a}}$ & $R^{2}$ & Linear range $(\mu \mathrm{g} / \mathrm{mL})$ & $\operatorname{LOD}^{\mathrm{b}}(\mu \mathrm{g} / \mathrm{mL})$ & $\operatorname{LOQ}^{\mathrm{c}}(\mu \mathrm{g} / \mathrm{mL})$ \\
\hline 1 & Rutin & $y=36771 x+4732.7$ & 0.9997 & $0.37 \sim 139.92$ & 0.18 & 0.37 \\
\hline 2 & Hyperoside & $y=45866 x-25252$ & 0.9999 & $0.34 \sim 126.65$ & 0.10 & 0.34 \\
\hline 3 & Isoquercitrin & $y=45714 x-5732.6$ & 0.9999 & $0.31 \sim 117.20$ & 0.10 & 0.31 \\
\hline 4 & $\begin{array}{l}3,3^{\prime}, 5,7-\text { Tetrahydroxy- } 4^{\prime}- \\
\text { methoxyflavanone }\end{array}$ & $y=6982.1 x-19647$ & 0.9999 & $2.67 \sim 1001.40$ & 0.89 & 2.67 \\
\hline 5 & $3^{\prime}, 5,5^{\prime}, 7$-Tetrahydroxyflavanone & $y=7495.0 x-9796.1$ & 1.0000 & $6.61 \sim 330.47$ & 1.32 & 5.29 \\
\hline 6 & Quercetin & $y=50230 x-22534$ & 0.9999 & $1.15 \sim 57.34$ & 0.23 & 0.92 \\
\hline 7 & $\begin{array}{l}3,3^{\prime}, 4^{\prime}, 5 \text {-Tetrahydroxy-7- } \\
\text { methoxyflavanone }\end{array}$ & $y=5499.5 x-15331$ & 0.9997 & $3.55 \sim 443.52$ & 0.88 & 3.55 \\
\hline 8 & Chrysosplenol C & $y=39377 x-14116$ & 0.9998 & $0.21 \sim 51.55$ & 0.07 & 0.21 \\
\hline 9 & Diosmetin & $y=1.0 E+5 x-14906$ & 1.0000 & $0.10 \sim 36.06$ & 0.03 & 0.10 \\
\hline 10 & Tamarixetin & $y=64551 x-12598$ & 0.9997 & $0.11 \sim 28.06$ & 0.04 & 0.11 \\
\hline 11 & 3,5,7-Trihydroxy-3', $4^{\prime}$-dimethoxyflavone & $y=70721 x-19615$ & 0.9999 & $0.11 \sim 95.68$ & 0.04 & 0.11 \\
\hline 12 & $3,3^{\prime}, 5$-Trihydroxy-4',7-dimethoxyflavanone & $y=7271.0 x-5822.3$ & 1.0000 & $0.86 \sim 747.94$ & 0.29 & 0.86 \\
\hline 13 & Blumeatin & $y=7339.9 x-8361.5$ & 1.0000 & $0.72 \sim 627.09$ & 0.24 & 0.72 \\
\hline 14 & Rhamnetin & $y=46787 x-11774$ & 1.0000 & $0.20 \sim 175.73$ & 0.07 & 0.20 \\
\hline 15 & $3^{\prime}, 4^{\prime}, 5$-Trihydroxy-3,7-dimethoxyflavone & $y=88162 x-11165$ & 0.9996 & $0.06 \sim 22.04$ & 0.02 & 0.06 \\
\hline 16 & Xanthoxylin & $y=10671 x-5373.4$ & 1.0000 & $0.99 \sim 173.27$ & 0.33 & 0.99 \\
\hline 17 & Ombuin & $y=1.9 E+5 x-18006$ & 0.9999 & $0.07 \sim 23.66$ & 0.02 & 0.05 \\
\hline 18 & 3,5-Dihydroxy-3', $4^{\prime}, 7$-trimethoxyflavone & $y=74640 x-9102.7$ & 0.9999 & $0.08 \sim 20.18$ & 0.03 & 0.08 \\
\hline
\end{tabular}

$y$ is the peak area and $x$ is the concentration of compound $(\mu \mathrm{g} / \mathrm{mL}) .{ }^{b} \mathrm{LOD}$ refers to the limit of detection, $\mathrm{S} / \mathrm{N}=2.3-3.6: 1$. ${ }^{\mathrm{c}} \mathrm{LOQ}$ refers to the limit of quantification, $\mathrm{S} / \mathrm{N}=8.1-10.3: 1$.

TABLE 2: The results of precision, repeatability, and stability.

\begin{tabular}{|c|c|c|c|c|c|c|c|c|}
\hline \multirow{2}{*}{ No. } & \multicolumn{3}{|c|}{ Intraday $(\mathrm{RSD}, \%, n=6)$} & \multicolumn{3}{|c|}{ Interday $(n=6)$} & \multirow{2}{*}{$\begin{array}{c}\text { Repeatability }(n=6) \\
\text { RSD (\%) }\end{array}$} & \multirow{2}{*}{$\begin{array}{c}\text { Stability }(n=6,18 \mathrm{~h}) \\
\operatorname{RSD}(\%)\end{array}$} \\
\hline & Low & Medium & High & Low & Medium & High & & \\
\hline 1 & 1.08 & 1.03 & 0.77 & 1.98 & 2.17 & 1.89 & 1.46 & 2.31 \\
\hline 2 & 0.31 & 0.40 & 0.39 & 1.14 & 1.07 & 0.84 & 1.03 & 1.26 \\
\hline 3 & 0.52 & 0.70 & 0.58 & 1.42 & 1.17 & 0.94 & 1.01 & 1.11 \\
\hline 4 & 1.86 & 1.86 & 1.60 & 2.13 & 2.30 & 1.92 & 1.97 & 2.44 \\
\hline 5 & 0.50 & 0.68 & 0.61 & 0.62 & 0.62 & 0.66 & 0.56 & 0.79 \\
\hline 6 & 0.57 & 0.59 & 0.60 & 1.04 & 0.88 & 0.99 & 0.69 & 0.90 \\
\hline 7 & 0.86 & 0.96 & 0.73 & 1.04 & 0.76 & 0.86 & 0.70 & 0.87 \\
\hline 8 & 1.08 & 1.38 & 1.28 & 1.73 & 1.74 & 2.09 & 1.38 & 1.27 \\
\hline 9 & 1.05 & 1.16 & 1.11 & 1.68 & 3.33 & 2.96 & 2.84 & 3.02 \\
\hline 10 & 0.98 & 1.53 & 0.98 & 1.40 & 1.21 & 1.28 & 1.04 & 1.81 \\
\hline 11 & 0.57 & 0.67 & 0.56 & 0.74 & 0.74 & 0.77 & 0.54 & 0.70 \\
\hline 12 & 0.65 & 0.65 & 0.50 & 0.79 & 0.79 & 0.52 & 0.60 & 0.63 \\
\hline 13 & 0.59 & 0.71 & 0.56 & 0.32 & 0.52 & 0.32 & 0.52 & 0.66 \\
\hline 14 & 0.70 & 0.66 & 0.62 & 0.52 & 0.87 & 1.11 & 0.82 & 0.93 \\
\hline 15 & 2.39 & 2.19 & 1.90 & 0.93 & 1.12 & 1.40 & 1.25 & 1.78 \\
\hline 16 & 1.21 & 1.13 & 1.02 & 0.64 & 0.58 & 0.68 & 1.31 & 1.58 \\
\hline 17 & 2.35 & 3.33 & 3.06 & 1.62 & 1.70 & 1.47 & 2.98 & 1.70 \\
\hline 18 & 0.99 & 0.60 & 0.45 & 0.67 & 0.70 & 0.86 & 0.65 & 0.74 \\
\hline
\end{tabular}

2.4. Method Validation. The linearity, limit of detection (LOD), limit of quantification (LOQ), precision, repeatability, stability, and recovery were checked for method validation.

\section{Results and Discussion}

3.1. Optimization of the Extraction Method. Four factors (including extraction methods, extraction solvents, solvent volume, and extraction time) were evaluated to get the most efficient extraction protocol. Sonication (15, 30, and $45 \mathrm{~min})$ and reflux (30 and $60 \mathrm{~min}$ ) in factorial experiments using $80 \%$ methanol and the reflux for $30 \mathrm{~min}$ showed the best extraction ability. Moreover, among 60\% methanol, $80 \%$ methanol, $100 \%$ methanol, $60 \%$ ethanol, and $80 \%$ ethanol, $80 \%$ methanol was the best solvent mixture and produced more chromatographic peaks. Furthermore, $25 \mathrm{~mL}$ of $80 \%$ methanol showed the best extraction efficiency compared to solvent volumes 50 and $100 \mathrm{~mL}$. Finally, samples extracted by reflux in $25 \mathrm{~mL}$ of $80 \%$ methanol for 30 min were selected for the extraction method (Figure 1).

3.2. Optimization of HPLC Parameters. To get an accepted resolution, separation parameters including analytical column, mobile phases, and elution gradient were assessed. The 
TABLE 3: Recovery of the targets $(n=3)$.

\begin{tabular}{|c|c|c|c|c|c|}
\hline No. & Original (mg) & Spiked (mg) & Found (mg) & Recovery $(\%)^{\mathrm{a}}$ & $\operatorname{RSD}(\%)^{\mathrm{b}}$ \\
\hline \multirow{3}{*}{1} & 0.36 & 0.23 & 0.59 & $100.95 \pm 3.95$ & 3.91 \\
\hline & 0.30 & 0.29 & 0.61 & $104.00 \pm 2.67$ & 2.56 \\
\hline & 0.24 & 0.35 & 0.59 & $102.15 \pm 3.37$ & 3.30 \\
\hline \multirow{3}{*}{2} & 0.33 & 0.21 & 0.55 & $102.84 \pm 4.08$ & 3.97 \\
\hline & 0.28 & 0.26 & 0.56 & $104.51 \pm 2.94$ & 2.81 \\
\hline & 0.22 & 0.32 & 0.54 & $102.64 \pm 2.41$ & 2.34 \\
\hline \multirow{3}{*}{3} & 0.32 & 0.20 & 0.52 & $103.76 \pm 3.67$ & 3.54 \\
\hline & 0.27 & 0.24 & 0.53 & $105.68 \pm 3.02$ & 2.86 \\
\hline & 0.21 & 0.29 & 0.51 & $103.49 \pm 2.38$ & 2.30 \\
\hline \multirow{3}{*}{4} & 2.40 & 1.67 & 4.02 & $96.90 \pm 4.18$ & 4.31 \\
\hline & 2.04 & 2.09 & 4.12 & $99.95 \pm 2.63$ & 2.63 \\
\hline & 1.60 & 2.50 & 4.09 & $99.53 \pm 2.31$ & 2.32 \\
\hline \multirow{3}{*}{5} & 0.54 & 0.33 & 0.88 & $100.70 \pm 4.80$ & 4.76 \\
\hline & 0.46 & 0.41 & 0.89 & $103.53 \pm 3.67$ & 3.55 \\
\hline & 0.36 & 0.50 & 0.87 & $102.48 \pm 3.64$ & 3.56 \\
\hline \multirow{3}{*}{6} & 0.11 & 0.06 & 0.17 & $103.95 \pm 4.36$ & 4.19 \\
\hline & 0.10 & 0.07 & 0.17 & $106.42 \pm 0.32$ & 0.30 \\
\hline & 0.08 & 0.09 & 0.17 & $109.92 \pm 0.51$ & 0.46 \\
\hline \multirow{3}{*}{7} & 0.74 & 0.44 & 1.21 & $104.71 \pm 1.64$ & 1.57 \\
\hline & 0.63 & 0.55 & 1.17 & $96.69 \pm 3.77$ & 3.89 \\
\hline & 0.50 & 0.67 & 1.13 & $95.37 \pm 2.22$ & 2.32 \\
\hline \multirow{3}{*}{8} & 0.10 & 0.05 & 0.16 & $108.99 \pm 3.63$ & 3.33 \\
\hline & 0.09 & 0.06 & 0.16 & $108.76 \pm 0.88$ & 0.81 \\
\hline & 0.07 & 0.08 & 0.15 & $107.31 \pm 1.03$ & 0.96 \\
\hline \multirow{3}{*}{9} & 0.03 & 0.03 & 0.05 & $103.56 \pm 2.84$ & 2.74 \\
\hline & 0.02 & 0.03 & 0.06 & $109.35 \pm 0.45$ & 0.41 \\
\hline & 0.02 & 0.04 & 0.06 & $104.19 \pm 0.37$ & 0.36 \\
\hline \multirow{3}{*}{10} & 0.05 & 0.03 & 0.08 & $101.56 \pm 3.61$ & 3.56 \\
\hline & 0.04 & 0.04 & 0.08 & $108.86 \pm 1.50$ & 1.38 \\
\hline & 0.03 & 0.04 & 0.08 & $107.88 \pm 0.30$ & 0.27 \\
\hline \multirow{3}{*}{11} & 0.10 & 0.07 & 0.17 & $102.90 \pm 4.55$ & 4.42 \\
\hline & 0.09 & 0.09 & 0.18 & $104.61 \pm 3.51$ & 3.36 \\
\hline & 0.07 & 0.10 & 0.18 & $103.53 \pm 2.47$ & 2.39 \\
\hline \multirow{3}{*}{12} & 0.84 & 0.53 & 1.39 & $102.48 \pm 4.30$ & 4.20 \\
\hline & 0.72 & 0.67 & 1.41 & $104.43 \pm 3.43$ & 3.28 \\
\hline & 0.56 & 0.80 & 1.39 & $103.05 \pm 2.48$ & 2.41 \\
\hline \multirow{3}{*}{13} & 0.67 & 0.45 & 1.13 & $102.81 \pm 4.19$ & 4.08 \\
\hline & 0.57 & 0.56 & 1.16 & $104.67 \pm 3.05$ & 2.91 \\
\hline & 0.45 & 0.67 & 1.14 & $103.34 \pm 2.43$ & 2.36 \\
\hline \multirow{3}{*}{14} & 0.24 & 0.13 & 0.36 & $97.59 \pm 3.55$ & 3.64 \\
\hline & 0.20 & 0.16 & 0.36 & $102.75 \pm 1.42$ & 1.39 \\
\hline & 0.16 & 0.19 & 0.36 & $106.26 \pm 0.52$ & 0.49 \\
\hline \multirow{3}{*}{15} & 0.02 & 0.02 & 0.04 & $103.40 \pm 4.19$ & 4.05 \\
\hline & 0.02 & 0.02 & 0.04 & $104.65 \pm 3.03$ & 2.90 \\
\hline & 0.01 & 0.02 & 0.04 & $100.95 \pm 2.78$ & 2.76 \\
\hline \multirow{3}{*}{16} & 0.19 & 0.12 & 0.31 & $95.85 \pm 2.17$ & 2.26 \\
\hline & 0.16 & 0.16 & 0.31 & $95.64 \pm 2.64$ & 2.76 \\
\hline & 0.13 & 0.19 & 0.31 & $95.03 \pm 2.21$ & 2.33 \\
\hline \multirow{3}{*}{17} & 0.01 & 0.02 & 0.03 & $105.40 \pm 0.99$ & 0.93 \\
\hline & 0.01 & 0.02 & 0.03 & $107.31 \pm 0.15$ & 0.14 \\
\hline & 0.01 & 0.03 & 0.03 & $109.30 \pm 0.52$ & 0.47 \\
\hline \multirow{3}{*}{18} & 0.03 & 0.02 & 0.05 & $104.16 \pm 4.70$ & 4.52 \\
\hline & 0.03 & 0.03 & 0.05 & $105.74 \pm 3.09$ & 2.93 \\
\hline & 0.02 & 0.03 & 0.05 & $105.15 \pm 2.54$ & 2.42 \\
\hline
\end{tabular}

${ }^{\mathrm{a}}$ Recovery $\%=[($ found amount - original amount $) /$ spiked amount $] \times 100 \% .{ }^{\mathrm{b}} \mathrm{RSD} \%=(\mathrm{SD} /$ mean $) \times 100 \%$. 
TABle 4: The contents of the 18 targets in the leaves of $B$. Balsamifera $(\mathrm{mg} / \mathrm{g}$, mean $\pm \mathrm{SD}, n=3)$.

\begin{tabular}{lcccc}
\hline No. & GZ20151001 & GZ20151002 & GX20151001 & YN20151001 \\
\hline 1 & $0.97 \pm 0.001$ & $1.01 \pm 0.002$ & $1.00 \pm 0.000$ & $0.47 \pm 0.012$ \\
2 & $0.91 \pm 0.003$ & $0.82 \pm 0.002$ & $0.45 \pm 0.007$ & $0.47 \pm 0.006$ \\
3 & $0.87 \pm 0.003$ & $0.77 \pm 0.003$ & $0.43 \pm 0.006$ & $0.45 \pm 0.002$ \\
4 & $6.54 \pm 0.050$ & $12.61 \pm 0.193$ & $4.39 \pm 0.046$ & $3.81 \pm 0.106$ \\
5 & $1.51 \pm 0.007$ & $0.96 \pm 0.006$ & $0.96 \pm 0.012$ & $2.38 \pm 0.003$ \\
6 & $0.32 \pm 0.003$ & $0.32 \pm 0.000$ & $0.28 \pm 0.002$ & $0.33 \pm 0.002$ \\
7 & $2.07 \pm 0.027$ & $2.48 \pm 0.002$ & $1.42 \pm 0.010$ & $3.29 \pm 0.001$ \\
8 & $0.27 \pm 0.004$ & $0.34 \pm 0.002$ & $0.28 \pm 0.001$ & $0.17 \pm 0.001$ \\
9 & $0.07 \pm 0.001$ & $0.08 \pm 0.000$ & $0.06 \pm 0.000$ & $0.01 \pm 0.000$ \\
10 & $0.13 \pm 0.001$ & $0.13 \pm 0.001$ & $0.07 \pm 0.001$ & $0.11 \pm 0.000$ \\
11 & $0.29 \pm 0.003$ & $0.20 \pm 0.001$ & $0.23 \pm 0.001$ & $0.28 \pm 0.000$ \\
12 & $2.34 \pm 0.020$ & $2.36 \pm 0.004$ & $1.78 \pm 0.012$ & $1.80 \pm 0.001$ \\
13 & $1.87 \pm 0.012$ & $2.17 \pm 0.004$ & $1.59 \pm 0.009$ & $1.31 \pm 0.000$ \\
14 & $0.66 \pm 0.005$ & $0.48 \pm 0.001$ & $0.30 \pm 0.003$ & $0.31 \pm 0.000$ \\
15 & $0.06 \pm 0.001$ & $0.06 \pm 0.000$ & $0.03 \pm 0.000$ & $0.06 \pm 0.000$ \\
16 & $0.53 \pm 0.001$ & $1.14 \pm 0.003$ & $0.50 \pm 0.003$ & $0.35 \pm 0.000$ \\
17 & $0.03 \pm 0.001$ & $0.02 \pm 0.000$ & $0.03 \pm 0.000$ & $0.01 \pm 0.000$ \\
18 & $0.09 \pm 0.001$ & $0.10 \pm 0.002$ & $0.00 \pm 0.000$ & $0.06 \pm 0.000$ \\
\hline
\end{tabular}

Elite Kromasil $\mathrm{C}_{18}$ column $(250 \mathrm{~mm} \times 4.6 \mathrm{~mm}, 5 \mu \mathrm{m})$ got the best resolution among all investigated columns. By comparing the strength of the response signals, the wavelength of $254 \mathrm{~nm}$ was selected for compounds $\mathbf{1 - 3}, \mathbf{6}, \mathbf{8 - 1 1}, \mathbf{1 4}, \mathbf{1 5}, \mathbf{1 7}$, and 18, while $289 \mathrm{~nm}$ was selected for compounds $4,5,7, \mathbf{1 2}$, 13, and 16 shown in Figure 2. In order to simultaneously detect all the 18 aforementioned compounds, in the analysis, both $254 \mathrm{~nm}$ and $289 \mathrm{~nm}$ were used concurrently. The typical HPLC chromatograms of the mixed standard solution are shown in Figure 3. The chromatographic purities of the 18 polyphenolic compound peaks were determined at multiple wavelengths by HPLC-PDA spectroscopy and the HPLC-MS method. In the HPLC-PDA spectroscopy, the purity factor of all peaks is within the calculated threshold limit. In the total ion chromatography obtained from HPLC-MS, we extracted the MS spectrum of the 18 peaks, and the $\mathrm{m} / \mathrm{z}$ values of base peaks corresponded with their molecular weight information (Figure 4).

3.3. Validation of the Developed Method. The established method was validated in terms of linearity, precision, stability, and accuracy. Linear regression equations (e.g., $y=a x+b)$ were constructed by plotting peak areas $(y)$ of each analyte against analyte concentrations $(x ; \mu \mathrm{g} / \mathrm{mL})$. The LOD and LOQ values were determined based on $\mathrm{S} / \mathrm{N}$ of 3 and 10, respectively. Table 1 summarizes the linearity, test range, limit of detection (LOD), and limit of quantification (LOQ). The linearity is indicated by the correlation coefficient $\left(R^{2}\right)$. All analytes showed linearity with $R^{2}$ between 0.9996 and 1.0000 in the test range. The LODs and LOQs for the 18 tested reference standards were around $0.02-1.32 \mu \mathrm{g} /$ $\mathrm{mL}$ and $0.05-5.29 \mu \mathrm{g} / \mathrm{mL}$, respectively.

Precision was evaluated by using intraday and interday variability. The intraday variability was assessed at three different concentration levels (low, medium, and high) with six replicates at each level within one day. The interday variability was tested in triplicate on the consecutive three days. The variations (RSD\%) for intra- and interday precision are shown in Table 2. The overall intra- and interday variations were less than $3.33 \%$. The repeatability was conducted using six replicates of the same sample, and the variations of repeatability were less than $2.98 \%$. The stability of the sample solution was investigated at $0,2,4,8,12$, and $18 \mathrm{~h}$. The RSD\% of peak areas of the analyzed compounds in the actual samples was $\leq 3.02 \%$, indicating that the analyzed compounds in the samples were stable at least $18 \mathrm{~h}$.

The recovery test was used to evaluate the accuracy of the method. Three different concentration levels (80\%, 100\%, and $120 \%$ of the concentration of the targets in a random sample) of the standard solutions were added into an actual sample. Triplicates were done for each level $(0.33 \mathrm{~g}, 0.30 \mathrm{~g}$, and $0.27 \mathrm{~g} \mathrm{~B}$. balsamifera powder). The recovery of each spiked reference standards was calculated by the formula recovery $\%=[$ (found amount-original amount $) /$ spiked amount $\times 100 \%$. The spike recoveries for 18 analyzed samples were $95.03-109.92 \%$ (Table 3).

Above data demonstrated that the developed HPLCPDA method was precise and accurate for quantitative determination of the 18 tested constituents in B. balsamifera.

3.4. Sample Determination. Herbs contain multiple bioactive components. Controlling the quality of herbs using a unique constituent is not an accepted method; thus, a tailored analytical method for each herb to evaluate multiple bioactive components simultaneously is needed. In the current study, we developed a simple and accurate assay method for simultaneous determination of 18 major compounds in the leaves of B. balsamifera.

The validated HPLC-PDA method was applied to the simultaneous determination of 18 bioactive components in the leaves of $B$. balsamifera collected from different regions in China. The results are shown in Table 4.

The content of compound 4 (3,3',5,7-tetrahydroxy- $4^{\prime}$ methoxyflavanone) showed the highest content among all tested compounds. Furthermore, the content of each studied components showed marked variations among different regions (Table 4). Therefore, it is necessary to establish a good agricultural practice (GAP) standard to grow medicinal plants with stable and consistent chemical ingredients.

\section{Conclusion}

In the present study, a simple and accurate HPLC-PDA analytic method was developed to quantify 18 bioactive compounds, simultaneously, in the leaves of B. balsamifera. This established HPLC method is helpful to improve the quality control of the leaves of B. balsamifera and related downstream products.

\section{Abbreviations}

HPLC: High-performance liquid chromatography PDA: $\quad$ Photodiode array detector

B. balsamifera: Blumea balsamifera

LOD: $\quad$ Limit of detection 
LOQ: $\quad$ Limit of quantification

RSD: $\quad$ Relative standard deviation.

\section{Data Availability}

The research data generated from this study are included within the article.

\section{Conflicts of Interest}

All the authors declare that there are no conflicts of interest.

\section{Acknowledgments}

This study was supported by the project of State Key Laboratory of Functions and Applications of Medicinal Plants, Guizhou Medical University (Grant no. FAMP201909K), the project of the Research on Traditional Chinese Medicine and Ethnic Medicine Science and Technology of Guizhou Provincial Administration of Traditional Chinese Medicine (Grant no. QZYY-2019-056), the National Key R\&D Program "Research on Modernization of Traditional Chinese Medicine" (Grant no. 2017YFC1702005), the Science and Technology Foundation of Guizhou Province of China (QKHPTRC[2019]5657 and QKHPTRC[2018]5772-001), and the Program for Excellent Young Talents of Zunyi Medical University (15zy-004).

\section{References}

[1] M. T. Nguyen, S. Awale, Y. Tezuka, Q. L. Tran, H. Watanabe, and S. Kadota, "Xanthine oxidase inhibitory activity of Vietnamese medicinal plants," Biological and Pharmaceutical Bulletin, vol. 27, no. 7, pp. 1414-1421, 2004.

[2] J. Ma, Q. Ren, B. Dong et al., "NO inhibitory constituents as potential anti-neuroinflammatory agents for $\mathrm{AD}$ from Blumea balsamifera," Bioorganic Chemistry, vol. 76, pp. 449-457, 2018.

[3] Y. Pang, D. Wang, Z. Fan et al., "Blumea balsamifera-A phytochemical and pharmacological review," Molecules, vol. 19, no. 7, pp. 9453-9477, 2014.

[4] C. Y. Ragasa, C. Co A. L. Kristin, and J. A. Rideout, "Antifungal metabolites from Blumea balsamifera," Natural Product Research, vol. 19, no. 3, pp. 231-237, 2005.

[5] T. Norikura, A. Kojima-Yuasa, M. Shimizu et al., "Anticancer activities and mechanisms of Blumea balsamifera extract in hepatocellular carcinoma cells," The American Journal of Chinese Medicine, vol. 36, no. 2, pp. 411-424, 2008.

[6] T. Norikura, A. Kojima-Yuasa, M. Shimizu et al., "Mechanism of growth inhibitory effect of Blumea balsamifera extract in hepatocellular carcinoma," Bioscience, Biotechnology, and Biochemistry, vol. 72, no. 5, pp. 1183-1189, 2008.

[7] N. Ruangrungsi, P. Tappayuthpijarn, P. Tantivatana, R. P. Borris, and G. A. Cordell, "Traditional medicinal plants of Thailand. I. Isolation and structure elucidation of two new flavonoids, (2R,3R)-dihydroquercetin- $4^{\prime}$-methyl ether and (2R,3R)-dihydroquercetin- $4^{\prime}, 7$-dimethyl ether from blurnea balsamifera," Journal of Natural Products, vol. 44, no. 5, pp. 541-545, 1981.

[8] Y. Lin, K. Long, and Y. Deng, "Studies on the chemical constituents of the Chinese medicinal plant Blumea balsamifera," Acta Scifntiarum Naturalium Universitatis Sunyaatseni, vol. 27, no. 2, pp. 77-80, 1988.
[9] N. Fazilatun, I. Zhari, M. Nornisah, and H. M. H. Mas Rosemal, "Phytochemical investigation on Blumea balsamifera DC," Journal of Tropical Medicinal Plants, vol. 2, no. 1, pp. 17-22, 2001.

[10] N. Fazilatun, I. Zhari, M. Nornisah, and H. M. H. Mas Rosemal, "Free radical-scavenging activity of organic extracts and of pure flavonoids of Blumea balsamifera DC leaves," Food Chemistry, vol. 88, no. 2, pp. 243-252, 2004.

[11] Y. Pang, Y. Zhang, L. Huang et al., "Effects and mechanisms of total flavonoids from Blumea balsamifera (L.) DC. On skin wound in rats," International Journal of Molecular Sciences, vol. 18, no. 12, pp. 2766-2788, 2017.

[12] N. Fazilatun, M. Nornisah, and I. Zhari, "Superoxide radical scavenging properties of extracts and flavonoids isolated from the leaves of Blumea balsamifera," Pharmaceutical Biology, vol. 43, no. 1, pp. 15-20, 2005.

[13] N. Saewan, S. Koysomboon, and K. Chantrapromma, "Antityrosinase and anti-cancer activities of flavonoids from Blumea balsamifera DC," Journal of Medicinal Plants Research, vol. 5, no. 6, pp. 1018-1025, 2011.

[14] H. Hasegawa, Y. Yamada, K. Komiyama et al., "Dihydroflavonol BB-1, an extract of natural plant Blumea balsamifera, abrogates trail resistance in leukemia cells," Blood, vol. 107, no. 2, pp. 679-688, 2006.

[15] N. Osaki, T. Koyano, T. Kowithayakorn, M. Hayashi, K. Komiyama, and M. Ishibashi, "Sesquiterpenoids and plasmin-inhibitory flavonoids from Blumea balsamifera," Journal of Natural Products, vol. 68, no. 3, pp. 447-449, 2005.

[16] S. B. Xu, W. F. Chen, H. Q. Liang, Y. C. Lin, Y. J. Deng, and K. H. Long, "Protective action of Blumeatin against experimental liver injuries," Acta Pharmacologica Sinica, vol. 14, no. 4, pp. 376-378, 1993.

[17] N. Fazilatun, I. Zhari, and M. Nornisah, "Xanthine oxidase inhibitory activities of extracts and flavonoids of the leaves of Blumea balsamifera," Pharmaceutical Biology, vol. 48, no. 12, pp. 1405-1412, 2010.

[18] Y. L. Huang, Y. X. Wen, Z. G. Zhao, and T. C. Zhu, "Determination of flavanones and flavanonols in Blumea balsamifera DC. by RP-HPLC," Guangxi Sciences, vol. 14, no. 2, pp. 140-142, 2007.

[19] N. Fazilatun, I. Zhari, K. Sundram, and M. Nornisah, "RPHPLC method for the quantitative analysis of naturally occurring flavonoids in leaves of Blumea balsamifera DC," Journal of Chromatographic Science, vol. 43, no. 8, pp. 416-420, 2005.

[20] S. Genovese, S. Fiorito, M. Locatelli, G. Carlucci, and F. Epifano, "Analysis of biologically active oxyprenylated ferulic acid derivatives in Citrus fruits," Plant Foods for Human Nutrition, vol. 69, no. 3, pp. 255-260, 2014.

[21] C. Ferrante, L. Recinella, M. Locatelli et al., "Protective effects induced by microwave-assisted aqueous harpagophytum extract on rat cortex synaptosomes challenged with amyloid B-peptide," Phytotherapy Research, vol. 31, no. 8, pp. 1257-1264, 2017.

[22] G. Zengin, E. J. Llorent-Martínez, M. L. F.-d. Córdova et al., "Chemical composition and biological activities of extracts from three Salvia species: S. blepharochlaena, S. euphratica var. leiocalycina, and S. verticillata subsp. amasiaca," Industrial Crops and Products, vol. 111, pp. 11-21, 2018.

[23] D. Tan, Q. Yan, H. Kang, W. Zeng, and H. Feng, "Chemical constituents of Blumea balsamifera DC," Natural Product Research \& Development, vol. 24, no. 6, pp. 718-721, 2012.

[24] Q. Yan, D. Tan, H. Kang, H. Feng, and W. Zeng, "Study on flavonoids constituents of Blumea balsamifera," Chinese Journal of Experimental Traditional Medical Formulae, vol. 18, no. 5, pp. 86-89, 2012. 